\title{
The changes of prevalence and etiology of pediatric pneumonia from National Emergency Department Information System in Korea, between 2007 and 2014
}

\author{
Eun Ju Shin, MD', Yunsun Kim, MS², Jin-Young Jeong, PhD, Yu Mi Jung, MS ${ }^{4}$, Mi-Hee Lee, MD ${ }^{5}$, Eun Hee Chung, MD, PhD \\ ${ }^{1}$ Department of Pediatrics, National Medical Center, Seoul, ${ }^{2} \mathrm{SCH}$ Biomedical Informatics Research Unit, Soonchunhyang University Seoul Hospital, Seoul, ${ }^{3} \mathrm{Hallym}$ Research \\ Institute of Clinical Epidemiology, Hallym University, Chuncheon, ${ }^{4}$ Medical Record Team, National Medical Center, Seoul, ${ }^{5}$ Department of Pediatrics, Incheon Medical Center, \\ Incheon, ${ }^{6}$ Department of Pediatrics, Chungnam National University School of Medicine, Daejeon, Korea
}

Purpose: Understanding changes in pathogen and pneumonia prevalence among pediatric pneumonia patients is important for the prevention of infectious diseases.

Methods: We retrospectively analyzed data of children younger than 18 years diagnosed with pneumonia at 117 Emergency Departments in Korea between 2007 and 2014.

Results: Over the study period, 329,380 pediatric cases of pneumonia were identified. The most frequent age group was $1-3$ years old (48.6\%) and the next was less than 12 months of age (17.4\%). Based on International Classification of Diseases, 10th revision diagnostic codes, confirmed cases of viral pneumonia comprised $8.4 \%$ of all cases, pneumonia due to Mycoplasma pneumoniae comprised 3.8\% and confirmed cases of bacterial pneumonia 1.3\%. The prevalence of confirmed bacterial pneumonia decreased from $3.07 \%$ in 2007 and $4.01 \%$ in 2008 to $0.65 \%$ in 2014 . The yearly rate of pneumococcal pneumonia also decreased from $0.47 \%$ in 2007 to $0.08 \%$ in 2014. A periodic prevalence of M. pneumoniae pneumonia (MP) was identified.

Conclusion: The increased number of patients with pneumonia, bacterial pneumonia, pleural effusion, and empyema in 2011 and 2013-2014 resulted from an MP epidemic. We provide evidence that the frequency of confirmed cases of bacterial pneumonia and pneumococcal pneumonia has declined from 2007 to 2014, which can simultaneously reflect the effectiveness of the pneumococcal conjugate vaccine.

Key words: Community acquired infections, Pneumonia, Interrupted time series analysis

\section{Introduction}

Pneumonia is the leading cause of hospitalization in developed countries and is associated with a high mortality rate worldwide. ${ }^{1)}$ The prevalence and mortality rate of pneumonia is particularly high in underdeveloped countries having poor healthcare resources and poor quality of sanitation. Understanding the incidence rate of pediatric pneumonia and identifying the pathogen for community-acquired pneumonia (CAP) forms the basis for diagnosis, therapeutic treatment, and intervention. In a study of 154 children hospitalized for CAP in the United States, between January 1999 and March 2000, a period prior to the universal use of pneumococcal conjugate vaccine (PCV), Michelow et al., ${ }^{2)}$ identified a bacterial pathogen in $60 \%$ of cases of pneumonia. The Streptococcus pneumoniae bacteria strain was identified in
Corresponding author: Eun Hee Chung, MD, PhD. Department of Pediatrics, Chungnam National University School of Medicine, 282 Munhwa-ro, Junggu, Daejeon 35015, Korea Tel: +82-42-280-7249

Fax: +82-42-255-3158

E-mail: ehchung@cnu.ac.kr http://orcid.org/0000-0001-9380-0151

Received: 19 September, 2017 Revised: 6 November, 2017 Accepted: 21 November, 2017

Copyright ( 2018 by The Korean Pediatric Society

This is an open-access article distributed under the terms of the Creative Commons Attribution NonCommercial License (http://creativecommons.org/ licenses/by-nc/4.0/n which permits unrestricted noncommercial use, distribution, and reproduction in any medium, provided the original work is properly cited. 
73\% of bacterial pathogen. S. pneumoniae was a common pathogen of CAP at that time. ${ }^{2)}$ The causal pathogen of CAP was very different in a survey of children under the age of 18 years who were hospitalized for pneumonia in designated hospitals in southern and Western part of US, between January 2010 and June 2012, a period after the universal use of PCV. ${ }^{1)}$ In this latter survey, a viral or bacterial cause was identified in $81 \%$ of cases, with more than one kind of virus detected in 66\% of cases. ${ }^{1)}$ An exclusive bacterial cause was identified in only $8 \%$ of cases, with both bacterial and viral causes identified in 7\% of cases. Therefore, by 2012, viruses had emerged as more significant pathogens of pneumonia than bacteria.

A multicenter retrospective study undertaken in Korea between 1996 and 2005 identified invasive bacterial infection as the most prevalent cause of pneumonia in children, with $S$. pneumoniae being the most common pathogen for bacterial pneumonia, meningitis and bacteremia among children 3 months to 5 years of age. ${ }^{3)}$ S. pneumoniae was also reported as a major pathogen for pediatric empyema in a multicenter survey conducted in Korea between 1999 and 2004. ${ }^{4}$ A single center in Korea identified the cause of lobar/ lobular pneumonia among children 2 to 15 years of age, between June 2006 and May 2008. Mycoplasma pneumoniae (50.7\%) was the most common organism in all age groups and bacteria was 5.9\%. S. pneumoniae (88.9\%) was the major cause of bacterial pneumonia including mixed infection. ${ }^{5}$

S. pneumoniae and Haemophilus influenzae were major bacterial pathogens of pneumonia. S. pneumoniae had caused 11\% of deaths in children aged under 5 years globally in the pre-PCV era. ${ }^{6}$ As medical costs associated with pneumonia are substantial, there have been continuous worldwide efforts to reduce the rate of pneumoniaassociated morbidity and mortality, including the use of vaccines. Changes in complications, morbidity, and the rate of pneumonia of PCV use were analyzed in the United States but not in Korea. The aim of the study was to describe the epidemiology of CAP in Korea, including yearly trends in incidence, frequency of viral and bacterial pathogens and the impact of PCV.

\section{Materials and methods}

This is a retrospective and observational study in which data from children and adolescents under 18 years of age, visited to one of the 117 Emergency Departments (EDs) in Korea between 1 January 2007 and 31 December 2014 were analyzed. The data were obtained from the National Emergency Department Information System (NEDIS) for children and adolescents under 18 years of age. The patients with diagnosis codes for CAP, based on International Classification of Disease, 10th revision diagnostic codes (Table 1) which was provided at the time of discharge from ED or after hospitalization were selected to identify eligible cases.

Categorical data was performed chi-square test, depending on age. Annual and seasonal distribution of ED visits were described by the number and $\%$ of total. The tau values were calculated using the Mann-Kendall method to analyze increasing or decreasing trends. Monthly incidence rate of diseases from data in 2008-2014 were decomposed and plotted into three components of trend, seasonality and remainder using LOESS procedure. Analyzes were performed

Table 1. International Classification of Diseases, 10th revision (ICD-10) diagnostic codes used in the study

\begin{tabular}{llll}
\hline ICD code & \multicolumn{1}{c}{ Diagnosis } & ICD code & \multicolumn{1}{c}{ Diagnosis } \\
\hline J10 & Influenza due to identified seasonal influenza virus & $\mathrm{J} 15.3$ & Pneumonia due to streptococcus, group B \\
$\mathrm{J} 10.0$ & Influenza with pneumonia, seasonal influenza virus identified & $\mathrm{J} 15.4$ & Pneumonia due to other streptococci \\
$\mathrm{J} 11$ & Influenza, virus not identified & $\mathrm{J} 15.5$ & Pneumonia due to Escherichia coli \\
$\mathrm{J} 11.0$ & Influenza with pneumonia, virus not identified & $\mathrm{J} 15.6$ & Pneumonia due to other gram-negative bacteria \\
$\mathrm{J} 12$ & Viral pneumonia, not elsewhere classified & $\mathrm{J} 15.7$ & Pneumonia due to Mycoplasma pneumoniae \\
$\mathrm{J} 12.0$ & Adenovirus pneumonia & $\mathrm{J} 15.8$ & Other bacterial pneumonia \\
$\mathrm{J} 12.1$ & Respiratory syncytial virus pneumonia & $\mathrm{J} 15.9$ & Bacterial pneumonia, unspecified \\
$\mathrm{J} 12.2$ & Parainfluenza pneumonia & $\mathrm{J} 16$ & Pneumonia due to other infectious organisms, not elsewhere \\
& & & classified \\
$\mathrm{J} 12.3$ & Human metapneumovirus pneumonia & $\mathrm{J} 16.0$ & Chlamydial pneumonia \\
$\mathrm{J} 12.8$ & Other viral pneumonia & $\mathrm{J} 16.8$ & Pneumonia due to other specified infectious organisms \\
$\mathrm{J} 12.9$ & Viral pneumonia, unspecified & $\mathrm{J} 17$ & Pneumonia in diseases classified elsewhere \\
$\mathrm{J} 13$ & Pneumonia due to Streptococcus pneumoniae & $\mathrm{J} 17.0$ & Pneumonia in bacterial diseases classified elsewhere \\
$\mathrm{J} 14$ & Pneumonia due to Hemophilus influenzae & $\mathrm{J} 17.1$ & Pneumonia in viral diseases classified elsewhere \\
$\mathrm{J} 15$ & Bacterial pneumonia, not elsewhere classified & $\mathrm{J} 18$ (including J18.0, 18.1, & Pneumonia, organism unspecified \\
& & $\mathrm{J} 18.2, \mathrm{J18.8,} \mathrm{J18.9)}$ & \\
$\mathrm{J15.0}$ & Pneumonia due to Klebsiella pneumoniae & $\mathrm{J} 86.0$ & Pyothorax with fistula \\
$\mathrm{J} 15.1$ & Pneumonia due to Pseudomonas & $\mathrm{J} 86.9$ & Pyothorax without fistula \\
$\mathrm{J15.2}$ & Pneumonia due to Staphylococcus & $\mathrm{J} 90$ & Pleural effusion
\end{tabular}


using SAS ver. 9.4 (SAS Institute Inc., Cary, NC, USA), with a $P$ value $\leq 0.05$ deemed significant.

Institutional Review Boards waived deliberation of this study.

\section{Results}

\section{CAP under 18 years of age during 2007-2014}

Over the 8-year study period, 329,380 children and adolescents were diagnosed with pneumonia, with a male-to-female ratio of $1: 0.8$. The age and yearly distribution of pneumonia cases, as well as the rate of hospitalization, are summarized in Table 2. Children 1 to 3 years old comprised the majority of cases (160,093 patients; 48.6\% of cases), followed by children under the age of 1 year (57,295 patients; $17.4 \%$ of cases). Adolescents, 13 to 18 years old, comprised the smallest proportion ( 21,012 patients, $6.4 \%$ of cases). The yearly prevalence of pediatric pneumonia increased from 30,521 cases in 2007 to 68,451 cases in 2014. Among the 329,380 cases, $45.6 \%$ (150,110 patients) were hospitalized and 1.1\% (3,770 patients) admitted to the intensive care unit (ICU). The rate of hospitalization was highest among patients under the age of 1 year (63.7\%), with the rate decreasing with age to a rate of $30.0 \%$ among patients 13 to 18 years old. The ICU admission rate was highest under 1 year old group (3.0\%), followed by 13 to 18 years old group (2.56\%; Table 2).

Although the incidence rate of ED visit increased from 2007 through 2014, the rate of hospitalization declined, from 63.4\% in
2007 to $38.2 \%$ in 2014. Peculiarly, the hospitalization rate was markedly lower in 2009, at 22.5\%. The yearly ICU admission rate declined over the study period, from 1.9\% in 2007 to $0.9 \%$ in 2014 (Table 2).

Overall, 66 deaths were reported, with a comparable rate of mortality of $0.01 \%$ to $0.03 \%$ for children under the age of 18 years (Table 2). Among children who died, 16 deaths (24.2\% of death) were caused by aspiration pneumonia, with 11 patients (16.7\% of cases) having a neurological disorder or congenital disease.

Over the 8-year period of the study, there were 2 peak patients number in February and November. In 2014, the rate of pneumonia was highest in February. In 2009, the number of patients was peak in November, followed by October (Fig. 1).

The prevalence of bacterial and viral pneumonia is summarized in Table 3. The etiology of pneumonia was not specified in $67.3 \%$ of cases (221,723 patients, diagnosis code J18-J18.9). Among the remaining cases with a clear etiology, viral pneumonia were diagnosed 27,607 patients; $8.4 \%$ of total pneumonia patients. The yearly prevalence of viral pneumonia varied between a low of 4.5\% in 2007 to a high of 31.3\% in 2009 during an influenza pandemic. When we broadly consider viral pathogens, including influenza, parainfluenza, and respiratory syncytial virus, as well as adenovirus and human metapneumovirus, the influenza virus was the most prevalent (11,553 patients, $41.8 \%$ of viral pneumonia), followed by the respiratory syncytial virus (4,771 patients, $17.3 \%$ of viral pneumonia).

Table 2. The clinical features of patients with pneumonia who visited Emergency Departments by age group and year in 2007-2014

\begin{tabular}{|c|c|c|c|c|c|c|c|c|}
\hline Variable & No. of patients & Hospitalization & $\begin{array}{c}\text { ICU } \\
\text { hospitalization }\end{array}$ & No. of deaths & $\begin{array}{l}\text { Bacterial confirmed } \\
\text { pneumonia* }^{*}\end{array}$ & $\begin{array}{l}\text { Pneumococcal } \\
\text { pneumonia }^{\dagger}\end{array}$ & Pleural effusion ${ }^{\ddagger}$ & Empyema $^{\S}$ \\
\hline \multicolumn{9}{|c|}{ Age group (yr) } \\
\hline$<1$ & 57,295 (17.4) & $36,470(63.7)$ & 1,706 (2.97) & $20(0.03)$ & $941(1.64)$ & $144(0.25)$ & $35(0.06)$ & $36(0.06)$ \\
\hline $1-3$ & $160,093(48.6)$ & $73,606(46.0)$ & $792(0.49)$ & $24(0.02)$ & $1,908(1.19)$ & $344(0.21)$ & $284(0.18)$ & $59(0.04)$ \\
\hline $4-6$ & $54,336(16.5)$ & 21,143 (38.9) & $323(0.59)$ & $6(0.01)$ & $590(1.09)$ & $69(0.13)$ & $304(0.56)$ & $7(0.01)$ \\
\hline $7-12$ & $36,644(11.1)$ & $12,688(34.6)$ & 409 (1.11) & $10(0.03)$ & $437(1.19)$ & $45(0.12)$ & $325(0.89)$ & $10(0.03)$ \\
\hline $13-18$ & $21,012(6.4)$ & $6,203(29.5)$ & $540(2.56)$ & $6(0.03)$ & 438 (2.08) & $20(0.09)$ & 331 (1.58) & $13(0.06)$ \\
\hline \multicolumn{9}{|l|}{ Year } \\
\hline 2007 & 30,521 & 1,9339 (63.4) & 578 (1.89) & $5(0.02)$ & $936(3.07)$ & $142(0.47)$ & $214(0.70)$ & $22(0.07)$ \\
\hline 2008 & 30,180 & $19,136(63.4)$ & $487(1.61)$ & $10(0.03)$ & $1210(4.01)$ & $115(0.38)$ & $144(0.48)$ & $17(0.06)$ \\
\hline 2009 & 47,263 & $10,611(22.5)$ & $353(0.75)$ & $5(0.01)$ & $215(0.45)$ & $37(0.08)$ & $114(0.24)$ & $6(0.01)$ \\
\hline 2010 & 35,888 & $18,848(52.5)$ & $404(1.13)$ & $12(0.03)$ & $357(0.99)$ & $121(0.34)$ & $209(0.58)$ & $13(0.04)$ \\
\hline 2011 & 41,194 & $20,747(50.4)$ & $394(0.96)$ & $5(0.01)$ & $416(1.01)$ & $85(0.21)$ & $242(0.59)$ & $20(0.05)$ \\
\hline 2012 & 39,056 & $16,666(42.7)$ & 397 (1.02) & $7(0.02)$ & $226(0.58)$ & $24(0.06)$ & $92(0.24)$ & $9(0.02)$ \\
\hline 2013 & 36,827 & $18,612(50.5)$ & $540(1.47)$ & $11(0.03)$ & $506(1.37)$ & $46(0.12)$ & $99(0.27)$ & $17(0.05)$ \\
\hline 2014 & 68,451 & 26,151 (38.2) & $617(0.90)$ & $11(0.02)$ & $448(0.65)$ & $52(0.08)$ & $165(0.24)$ & $21(0.03)$ \\
\hline Total & 329,380 & $150,110(45.6)$ & $3,770(1.14)$ & $66(0.02)$ & $4,314(1.30)$ & $622(0.18)$ & $1,279(0.38)$ & $125(0.03)$ \\
\hline$P$ value & & $<0.0001$ & $<0.0001$ & 0.0154 & $<0.0001$ & $<0.0001$ & $<0.0001$ & 0.0001 \\
\hline
\end{tabular}

Values are presented as number (\%).

${ }^{\star} \mid \mathrm{CD}-10$ diagnostic codes; J13, J14, J15-J15.9 (except J15.7)+J17.0. ${ }^{\dagger}$ ICD-10 diagnostic codes; J13. ${ }^{\ddagger} \mathrm{ICD}-10$ diagnostic codes; J90. ${ }^{\S} \mathrm{ICD}-10$ diagnostic codes; J860, J869. 


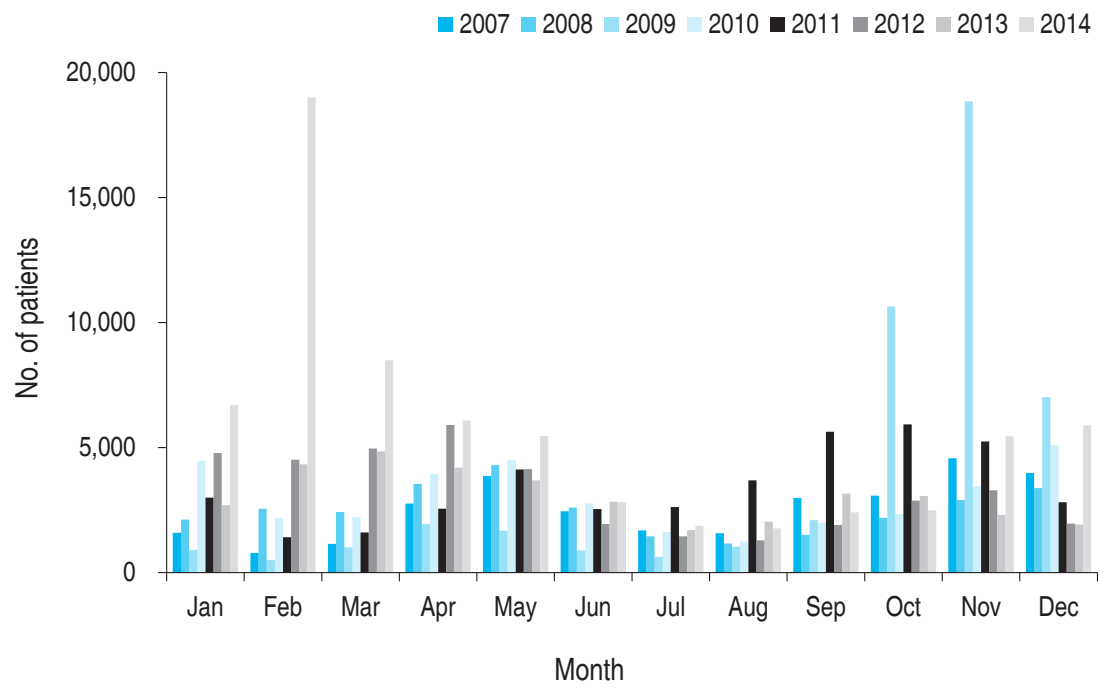

Fig. 1. Monthly distribution of community-acquired pneumonia in children and adolescents younger than 18 years, January 2007 to December 2014, Korea.

Table 3. Community-acquired pneumonia: identified pathogens in children and adolescents under 19 years of age in 2007-2014

\begin{tabular}{|c|c|c|c|c|c|c|c|c|c|}
\hline Cause of pneumonia & No. of patients & 2007 & 2008 & 2009 & 2010 & 2011 & 2012 & 2013 & 2014 \\
\hline Viral pneumonia* & $27,607(8.4)$ & $1,245(4.5)$ & $1,338(4.8)$ & $8,637(31.3)$ & $3,160(11.5)$ & $2,024(7.3)$ & 2,302 (8.3) & $3,228(11.7)$ & $5,673(20.6)$ \\
\hline Influenza virus & $11,553(3.5)$ & $153(1.3)$ & $105(0.9)$ & $7,840(67.9)$ & $1,421(12.3)$ & $172(1.5)$ & $427(3.7)$ & 337 (2.9) & $1,098(9.5)$ \\
\hline Respiratory syncytial virus & $4,771(1.4)$ & $145(3.0)$ & $234(4.9)$ & $86(1.8)$ & $477(10)$ & $488(10.2)$ & $633(13.3)$ & 917 (19.2) & $1,791(37.5)$ \\
\hline Parainfluenza virus & $954(0.3)$ & $52(5.5)$ & $33(3.5)$ & $32(3.4)$ & $71(7.4)$ & $61(6.4)$ & $101(10.6)$ & $243(25.5)$ & $361(37.8)$ \\
\hline Adenovirus & $876(0.26)$ & $33(3.8)$ & $29(3.3)$ & $25(2.8)$ & $84(9.6)$ & $41(4.7)$ & $45(5.1)$ & $346(39.5)$ & $273(31.2)$ \\
\hline Metapneumovirus & 26) & $0(0)$ & $0(0)$ & $0(0)$ & $0(0)$ & 50158 & $53(6$ & $217(24.9)$ & $550(63.2)$ \\
\hline $\begin{array}{l}\text { Bacterial confirmed } \\
\text { pneumonia }^{\dagger}\end{array}$ & $4,316(1.3)$ & $936(21.7)$ & $1,210(28.0)$ & $215(5.0)$ & $357(8.3)$ & $416(9.6)$ & $226(5.2)$ & $506(11.7)$ & $448(10.4)$ \\
\hline S. pneumoniae & $622(0.2)$ & $142(22.8)$ & $115(18.5)$ & $37(5.9)$ & $121(19.4)$ & 85 (13.7) & $24(3.9)$ & $46(7.4)$ & $52(8.4)$ \\
\hline S. aureus & $55(0.02)$ & 10 (18.2) & $14(25.5)$ & $7(12.7)$ & $3(5.5)$ & $5(9.1)$ & $2(3.6)$ & $7(12.7)$ & $7(12.7)$ \\
\hline H. influenza & $121(0.04)$ & $6(5.0)$ & $17(14.0)$ & $3(2.5)$ & $30(24.8)$ & $16(13.2)$ & $8(6.6)$ & $29(24.0)$ & $12(9.9)$ \\
\hline Mycoplasma pneumoniae & $12,635(3.8)$ & 1,935 (15.3) & $951(7.5)$ & $621(4.9)$ & $1,066(8.4)$ & $3,638(28.8)$ & $1,569(12.4)$ & $974(7.7)$ & $1,881(14.9)$ \\
\hline Unspecified pneumonia $^{\ddagger}$ & $221,723(67.3)$ & 27,035 (12.2) & $26,192(11.8)$ & $14,333(6.5)$ & $25,911(11.7)$ & $37,274(16.8)$ & $28,118(12.7)$ & $27,694(12.5)$ & $35,166(15.9)$ \\
\hline
\end{tabular}

Values are presented as number (\%).

S. pneumoniae, Streptococcus pneumoniae; S. aureus, Staphylococcus aureus; H. influenza, Haemophilus influenzae.

${ }^{*}$ ICD-10 diagnostic codes; J10, J10.0, J11, J11.0, J12-J12.9, J17.1. ${ }^{\dagger} \mathrm{ICD}-10$ diagnostic codes; J13, J14, J15-J15.9 (except J15.7)+J17.0. ${ }^{\ddagger} \mathrm{ICD}-10$ diagnostic codes; J18, J18.0, J18.1, J18.2, J18.8, J18.9.

Bacterial confirmed pneumonia was identified in $1.3 \%$ cases (4,316 patients, diagnosis codes J13, J14, J15-J15.9 excluding J15.7, J17.0). The yearly incidence of bacterial pneumonia decreased from 3.07\% in 2007 and 0.65\% in 2014 (Table 2). Among patients with bacterial pneumonia, 622 patients were diagnosed with pneumococcal pneumonia, with the yearly rate decreasing from $0.47 \%$ in 2007 to $0.08 \%$ in 2014 (Table 2).

M. pneumoniae pneumonia (MP) was diagnosed in 3.8\% of cases (12,635 patients; Table 3). The 8-year monthly prevalence of MP is shown in Fig. 2. There was an increase in the number of patients in 2007. The prevalence of MP rose again in 2010 and 2011, due to a large epidemic, burgeoning again in early 2014 (Table 3, Fig. 2).
Pleural effusion was identified in $0.4 \%$ of total cases (1,279 patients), accounting for 1.6\% (68 patients) of cases of bacterial pneumonia and 2.0\% (251 patients) of cases of MP. The yearly rate of patients presenting with pneumonia and pleural effusion is summarized in Table 2 and varied between $0.2 \%$, in 2009 and 2012, and 0.7\% in 2007. Empyema was identified in 125 patients (0.03\% of cases), with the yearly rate varying between $0.01 \%$ in 2009 and $0.07 \%$ in 2007 (Table 2).

The annual proportion of patients with pneumococcal pneumonia and age of patients are reported in Table 2, with significant yearly and age-specific differences identified. The expected number of patients with bacterial pneumonia, pneumococcal pneumonia, pleu- 


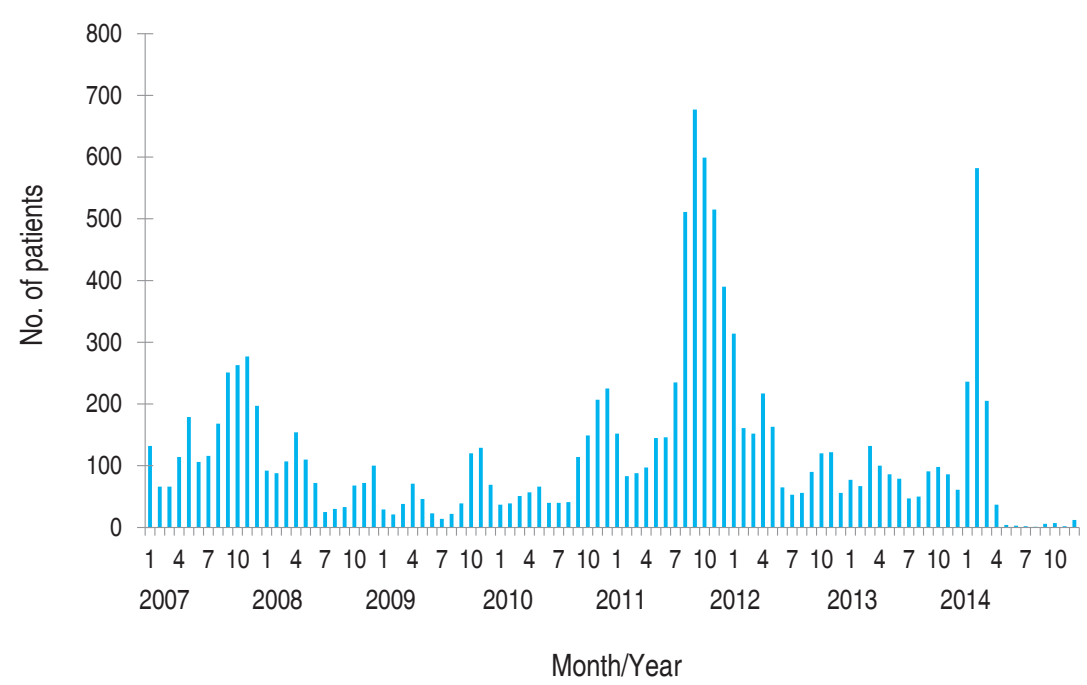

Fig. 2. Monthly distribution of Mycoplasma pneumoniae pneumonia in children and adolescents younger than 18 years, January 2007 to December 2014, Korea.

Bacterial pneumonia

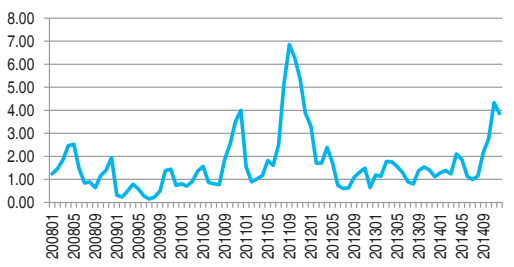

Pleural effusion

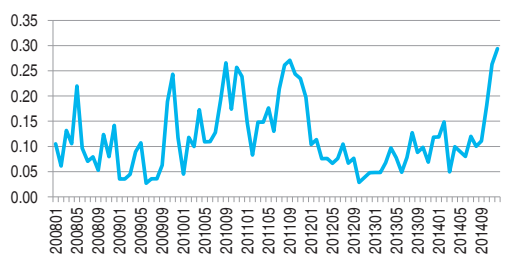

Pneumococcal pneumonia

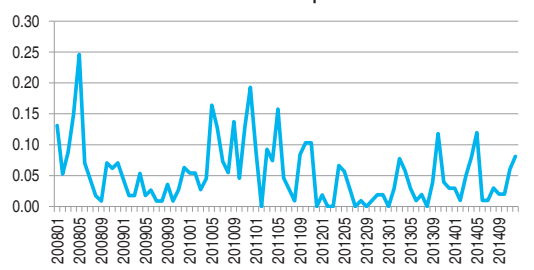

Empyema

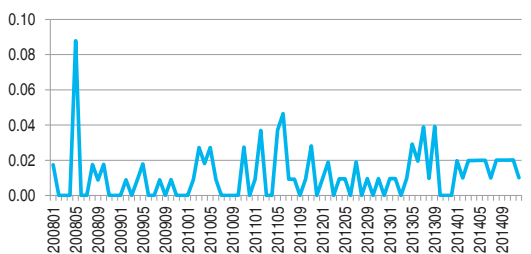

Fig. 3. The monthly incidence of bacterial pneumonia, pneumococcal pneumonia, pleural effusion and empyema in children and adolescents younger than 18 years per 100,000 population in 2008-2014 (Korean Statistical Information Service did not provide monthly population in 2007).

ral effusion, and empyema per 100,000 population between the ages of birth and 18 years is shown in Fig. 3. The upsurge of bacterial pneumonia in 2011 is presumed to have been associated with the increased prevalence of pneumonia-related complications, including pleural effusion and empyema, in 2011. The expected number of patients with pneumococcal pneumonia also rose in 2011, although, overall, there was a decreasing trend in the prevalence of bacterial pneumonia, pneumococcal pneumonia, pleural effusion, and empyema compared to that in 2007.

\section{Time series analysis}

There was no decreasing or increasing trend in the number of patients with bacterial pneumonia, pneumococcal pneumonia, pleural effusion, and empyema per 100,000 population per year during the period from 2007 to 2014 (Table 4). In the annual deaths, stratified by age, the number of deaths per 10 million people in the 13 to 18 -year-old group was significantly increased ( $t a u=$ 0.725, $P=0.0239$ ) (Table 4). In annual ICU hospitalized patients, an increasing trend was observed in the age group 7-12 years ( $\mathrm{tau}=$ 0.643, $P=0.0354$ ) (Table 4). Since Korean Statistical Information Service did not provide the monthly population in 2007, the monthly trend test was conducted for the period from 2008 to 2014. Bacterial pneumonia and empyema showed monotonic trend taking 12-month seasonality into account. The bacterial pneumonia and 
Table 4. Time series trend test of incidence, death and intensive care unit (ICU) hospitalization stratified by age in 2007-2014

\begin{tabular}{|c|c|c|c|c|c|c|c|c|c|c|}
\hline Varible & 2007 & 2008 & 2009 & 2010 & 2011 & 2012 & 2013 & 2014 & $\begin{array}{l}\text { Mann-Kendall } \\
\text { test (tau) }\end{array}$ & $P$ value \\
\hline \multicolumn{11}{|c|}{ Annual incidence per 100,000 population (0-18 yr) } \\
\hline Bacterial pneumonia* $^{*}$ & 23.7 & 17.9 & 7.15 & 19.6 & 37.9 & 17.4 & 15.9 & 24.2 & -0.0714 & 0.9015 \\
\hline Pneumococcal pneumonia $^{\dagger}$ & 1.23 & 1.01 & 0.33 & 1.10 & 0.79 & 0.23 & 0.45 & 0.52 & -0.429 & 0.1736 \\
\hline Pleural effusion ${ }^{\ddagger}$ & 1.86 & 1.27 & 1.02 & 1.90 & 2.25 & 0.88 & 0.97 & 1.65 & -0.0714 & 0.9015 \\
\hline Empyema $^{\S}$ & 0.19 & 0.15 & 0.05 & 0.12 & 0.19 & 0.09 & 0.17 & 0.21 & -0.0364 & 1.0000 \\
\hline \multicolumn{11}{|c|}{ Annual death per $10,000,000$ population stratified by age } \\
\hline$<1 \mathrm{yr}$ & 44.7 & 131.2 & 46.0 & 68.7 & 66.7 & 0 & 22.6 & 71.3 & -0.0714 & 0.9015 \\
\hline $1-3 \mathrm{yr}$ & 21.82 & 22.02 & 14.40 & 28.50 & 14.36 & 14.43 & 35.44 & 21.2 & 0.0714 & 0.9015 \\
\hline $4-6$ yr & 0 & 0 & 0 & 7.25 & 0 & 14.34 & 0 & 21.5 & 0.535 & 0.1148 \\
\hline $7-12 \mathrm{yr}$ & 0 & 2.57 & 2.69 & 8.49 & 0 & 6.28 & 6.67 & 3.48 & 0.4 & 0.2125 \\
\hline $13-18$ yr & 0 & 0 & 0 & 2.37 & 0 & 2.45 & 7.51 & 2.58 & 0.725 & 0.0239 \\
\hline \multicolumn{11}{|c|}{ Annual ICU hospitalization per 100,000 population stratified by age } \\
\hline$<1 \mathrm{yr}$ & 71.1 & 47.4 & 23.2 & 41.5 & 38.7 & 43.7 & 54.4 & 65.1 & 0.143 & 0.7105 \\
\hline $1-3 y r$ & 8.2 & 9.9 & 5.0 & 5.5 & 5.8 & 5.2 & 7.7 & 9.6 & 0.071 & 0.9015 \\
\hline $4-6 \mathrm{yr}$ & 3.2 & 2.1 & 3.6 & 2.7 & 2.9 & 2.1 & 2.9 & 2.9 & -0.077 & 0.8978 \\
\hline $7-12 \mathrm{yr}$ & 0.9 & 1.0 & 1.9 & 1.5 & 1.1 & 1.3 & 2.1 & 2.3 & 0.643 & 0.0354 \\
\hline $13-18$ yr & 1.5 & 1.6 & 1.4 & 1.3 & 1.5 & 1.3 & 2.2 & 2.5 & 0.222 & 0.5298 \\
\hline
\end{tabular}

${ }^{\star} \mid \mathrm{CD}-10$ diagnostic codes; J13, J14, J15-J15.9 (except J15.7)+J17.0. ${ }^{\dagger}$ ICD-10 diagnostic codes; J13. ${ }^{\ddagger} \mathrm{ICD}-10$ diagnostic codes; J90. ${ }^{\circledR} \mathrm{ICD}-10$ diagnostic codes; J860, J869.
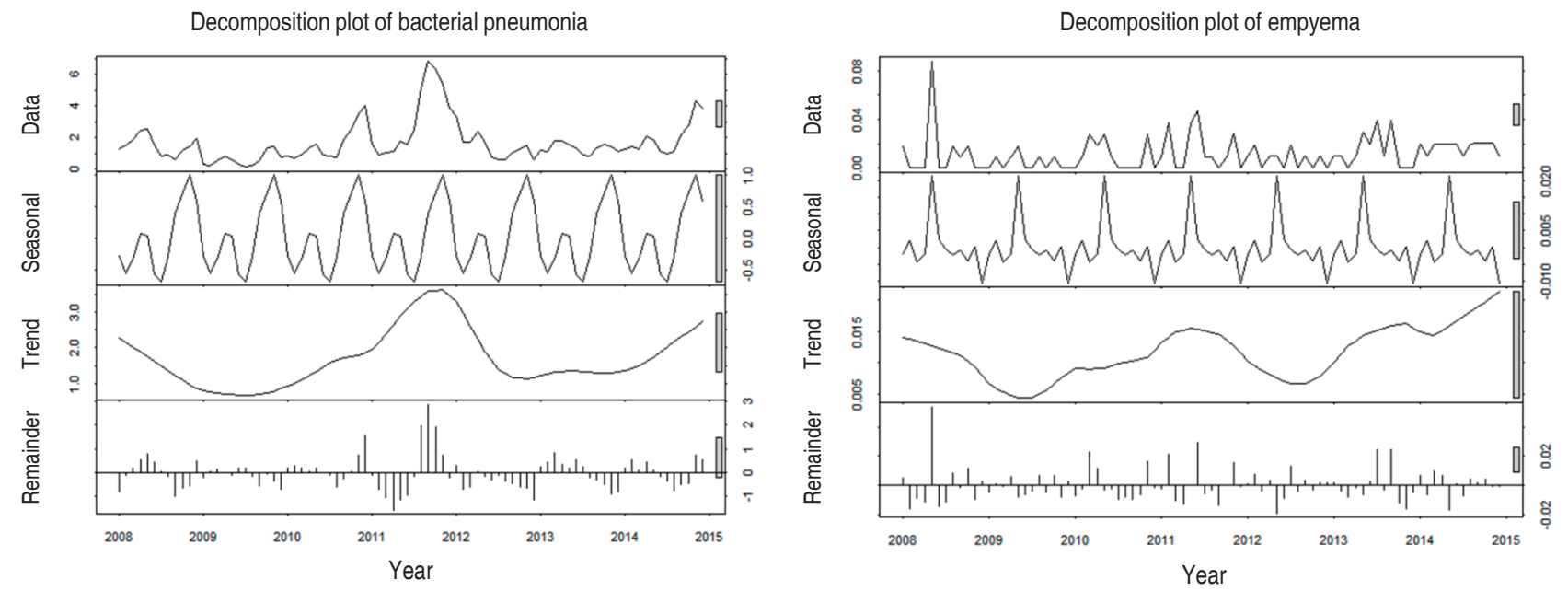

Fig. 4. Seasonal trend decomposition plot of monthly incidence for bacterial pneumonia and empyema in 2008-2014 (Korean Statistical Information Service did not provide monthly population in 2007).

empyema peaks were in December and May, respectively (Figs. 3, 4; Table 5).

In time series trend test of annual incidence of bacterial pneumonia, pneumococcal pneumonia, pleural effusion and empyema per 100,000 population, there were not significant increasing or decreasing trend (Table 6).
Table 5. Results of the Mann-Kendall trend test with pneumonia based on the seasonal pattern for 12 months (2008-2014)

\begin{tabular}{lcc}
\hline \multirow{2}{*}{ Variable } & \multicolumn{2}{c}{ Seasonal Mann-Kendall trend test } \\
\cline { 2 - 3 } & Tau & $P$ value \\
\hline Bacterial pneumonia* $^{*}$ & 0.238 & 0.0093 \\
Pneumococcal pneumonia $^{\dagger}$ & -0.179 & 0.0508 \\
Pleural effusion $^{\ddagger}$ & 0.0476 & 0.6029 \\
Empyema $^{\S}$ & 0.339 & 0.0004 \\
\hline${ }^{*}$ ICD-10 diagnostic codes; J13, J14, J15-J15.9 (except J15.7)+J17.0. ${ }^{\dagger}$ ICD- \\
10 diagnostic codes; J13. ${ }^{\ddagger}$ ICD-10 diagnostic codes; J90. ${ }^{\S}$ ICD-10 diagnostic \\
Codes; J860, J869.
\end{tabular}


Table 6. Time series trend test of annual incidence of bacterial pneumonia, pneumococcal pneumonia, pleural effusion, and empyema per 100,000 population

\begin{tabular}{|c|c|c|c|c|c|c|c|c|c|c|}
\hline Varible & 2007 & 2008 & 2009 & 2010 & 2011 & 2012 & 2013 & 2014 & $\begin{array}{l}\text { Mann-Kendall } \\
\text { test (tau) }\end{array}$ & $P$ value \\
\hline \multicolumn{11}{|c|}{ Annual incidence of bacterial pneumonia per 100,000 population by age group } \\
\hline$<1 \mathrm{yr}$ & 56.54 & 74.56 & 10.59 & 27.95 & 36.67 & 20.31 & 37.25 & 34.71 & -0.1429 & 0.7105 \\
\hline $1-3 \mathrm{yr}$ & 86.61 & 69.57 & 20.24 & 67.20 & 107.95 & 68.13 & 58.41 & 76.72 & 0 & 1 \\
\hline $4-6 \mathrm{yr}$ & 45.86 & 26.47 & 15.66 & 38.95 & 84.62 & 32.63 & 26.38 & 42.47 & 0.2143 & 0.5362 \\
\hline $7-12 \mathrm{yr}$ & 10.06 & 6.29 & 4.59 & 12.13 & 29.92 & 7.56 & 6.53 & 15.56 & 0.2143 & 0.5362 \\
\hline $13-18$ yr & 3.53 & 2.55 & 1.87 & 2.96 & 5.78 & 2.28 & 1.83 & 3.81 & -0.0714 & 0.9015 \\
\hline \multicolumn{11}{|c|}{ Annual incidence of pneumococcal pneumonia per 100,000 population by age group } \\
\hline$<1 \mathrm{yr}$ & 71.1 & 47.4 & 23.2 & 41.5 & 38.7 & 43.7 & 54.4 & 65.1 & -0.3571 & 0.2655 \\
\hline $1-3 \mathrm{yr}$ & 5.24 & 4.55 & 1.44 & 5.63 & 3.16 & 0.94 & 1.63 & 2.19 & -0.3571 & 0.2655 \\
\hline $4-6 \mathrm{yr}$ & 0.93 & 0.86 & 0.28 & 0.58 & 1.02 & 0.14 & 0.57 & 0.36 & -0.4286 & 0.1735 \\
\hline $7-12 \mathrm{yr}$ & 0.35 & 0.21 & 0.11 & 0.23 & 0.09 & 0.03 & 0.10 & 0.14 & -0.4286 & 0.1735 \\
\hline $13-18 \mathrm{yr}$ & 0.15 & 0.07 & 0.09 & 0.09 & 0 & 0 & 0.05 & 0.03 & -0.5189 & 0.1024 \\
\hline \multicolumn{11}{|c|}{ Annual incidence of pleural effusion per 100,000 population by age group } \\
\hline$<1 \mathrm{yr}$ & 2.23 & 1.09 & 1.15 & 0.69 & 0.22 & 0.66 & 0.90 & 0.95 & -0.3571 & 0.2655 \\
\hline $1-3 \mathrm{yr}$ & 4.00 & 3.23 & 1.37 & 3.49 & 3.73 & 1.30 & 1.35 & 1.98 & -0.1429 & 0.7105 \\
\hline $4-6 \mathrm{yr}$ & 2.96 & 1.60 & 2.31 & 3.70 & 5.70 & 1.29 & 0.99 & 2.72 & -0.0714 & 0.9015 \\
\hline $7-12 \mathrm{yr}$ & 1.40 & 0.80 & 0.86 & 1.81 & 2.08 & 0.47 & 0.63 & 1.32 & -0.0714 & 0.9015 \\
\hline $13-18 \mathrm{yr}$ & 1.10 & 0.96 & 0.59 & 0.99 & 0.98 & 0.93 & 1.08 & 1.47 & 0.2143 & 0.5362 \\
\hline \multicolumn{11}{|c|}{ Annual incidence of empyema per 100,000 population by age group } \\
\hline$<1 \mathrm{yr}$ & 2.23 & 0.66 & 0.23 & 0 & 1.56 & 0.87 & 1.81 & 0.71 & 0 & 1 \\
\hline $1-3 \mathrm{yr}$ & 0.65 & 0.51 & 0.07 & 0.57 & 0.72 & 0.29 & 0.35 & 1.06 & -0.0412 & 1 \\
\hline $4-6 \mathrm{yr}$ & 0.06 & 0.07 & 0.07 & 0.15 & 0.00 & 0.07 & 0.00 & 0.07 & 0 & 1 \\
\hline $7-12 y r$ & 0.02 & 0.05 & 0.05 & 0.03 & 0.03 & 0.00 & 0.07 & 0.03 & 0 & 1 \\
\hline $13-18 \mathrm{yr}$ & 0.02 & 0.10 & 0.02 & 0.05 & 0.05 & 0.00 & 0.05 & 0.03 & -0.0772 & 0.8978 \\
\hline
\end{tabular}

ICU, intensive care unit.

\section{Discussion}

Over the 8-year period of our study, from 2007 to 2014, the prevalence of ED visits for pediatric pneumonia increased, spiking in 2009 and 2014. According to the census published by Statistics Korea, the increase in children and adolescents with pneumonia between 2007 and 2014 occurred amid an overall decrease in the number of children under the age of 18 years in the general population, from 24,338 cases per total population of 100,000 in 2005 to 15,367 cases per total population of 100,000 in $2010 .^{7)}$ The prevalence ED visits for pediatric pneumonia spiked during in 2009 due to an influenza epidemic and in 2011 and 2014 due to a cyclical MP epidemic that recurs every 3 to 4 years in Korea. ${ }^{8-10)}$

The pathogens for CAP varied widely based on age, region, and season. Bacteria and viruses were the most typical pathogens, with M. pneumoniae being a common pathogen among preschool-aged children. The difficulty in identifying the causative pathogen due to difficulty in collecting specimen, such a sputum or mouth culture, for microbiological diagnosis, likely explains why an etiology was not specified in two-thirds of our cases. Among those with a clear etiology, viral pathogens were the most common, followed by $M$. pneumoniae and bacteria. In our case series from 2007 through 2014, the highest prevalence of viral pneumonia occurred in 2009 due to an outbreak of H1N1 influenza, although the prevalence of viral pneumonia did increase from 2007 through 2014 (Table 3). We speculate that the introduction of multiplex real time-polymerase chain reaction (RT-PCR) improved the diagnosis of viral pathogens of pneumonia in Korea over the 8-year period of our study. ${ }^{11,12)} \mathrm{In}$ fact, our data clearly indicate this, with an increase in the diagnosis of human metapneumovirus pneumonia using multiplex RT-PCR since 2011. Multiplex RT-PCR is a test for the addition of human metapneumovirus, coronavirus, and rhinovirus to conventional respiratory virus detection (respiratory syncytial virus, adenovirus, influenza virus, parainfluenza virus). In Korea, a study on respiratory virus using multiplex RT-PCR has been started in $2006^{13,14)}$ and was gradually expanded. ${ }^{11,14)}$ Human metapneumovirus was a newly discovered virus, and it would take time for the ICD code to be created and used in Korea.

Seven-valent PCV (PCV7) was developed in 2000 and universally used to effectively prevent $S$. pneumonia, a major pathogen for 
severe invasive bacterial diseases in addition to pneumonia, in children under the age of 2 years. ${ }^{15,16)}$ The efficacy of the PCV7 for preventing invasive infections and acquiring herd immunity has been confirmed in several studies, including through monitoring by the US Centers for Disease Control. ${ }^{15,17)}$ The PCV has been associated with a $>25 \%$ decrease in streptococcal pneumonia, as well as lowering the risk of invasive pneumococcal disease and of pneumonia caused by antibiotics-resistant pneumococcal strain. ${ }^{15}$ In Korea, the increasing trend in deep infection caused by one of the subtypes of $S$. pneumoniae in children under the age of 5 years from 1991 to 2003 was reversed in 2004 to 2006, presumably due to PCV immunization programs implemented in November 2003. ${ }^{18)}$ Our data indicates the presence of a herd immunity among unvaccinated individuals, with a decrease in the prevalence of bacterial and pneumococcal pneumonia among children 7 to 18 years of age, although the PCV7 optional immunization program was only introduced in Korea in November 2003. ${ }^{19)}$

MP usually affects preschool- and school-aged children, with a cyclical epidemic occurring every 3 to 4 years in Korea. ${ }^{8,10)}$ According to an epidemiological survey conducted by the Korea National Research Institute of Health, the incidence of mycoplasma infection increased in 2007, with a subsequent upsurge between 2010 and 2011. ${ }^{9)}$ MP is associated with diverse radiological findings, including concomitant pleural effusion and lobar pneumonia, which makes its differential diagnosis from bacterial pneumonia difficult merely based on clinical presentations and chest radiographs. ${ }^{20,21)}$ Further, it is not uncommon for M. pneumoniae infection to coexist with infections from other pathogens. ${ }^{22)}$ Therefore, the prevalence and effects of a M. pneumoniae infection should be considered whenever the prevalence of bacterial pneumonia is evaluated. Over our 8-year study period, although not significant, though, the prevalence of bacterial pneumonia decreased between 2007 and 2014, with the exception of a unique spike in 2011. The increase in the total number of patients with pneumonia, the number of patients with bacterial pneumonia, the number of patients with pleural effusion and empyema in 2011 and the prevalence of bacterial pneumonia among children in the 4-6 and 7-12 years age groups in 2011 are speculated to have resulted from an nationwide MP epidemic extending from late 2010 to early 2012 (Fig. 2). The increased prevalence three years later (2013-2014) also likely resulted from a MP epidemic.

When prevalence was analyzed according to age groups, pneumonia in the age group of 1 to 3 years accounted for the largest proportion of all cases of pediatric pneumonia. However, among all age groups, the prevalence of bacterial and pneumococcal pneumonia was lower in 2014 than in 2007. Notably, the decreasing trend in the prevalence of pneumococcal pneumonia, and concomitant pleural effusion or empyema (Table 2), suggests that, similar to other countries, the introduction of PCV in Korea had a specific effectiveness against pneumococcal pneumonia and its compli- cations.

According to research data published outside of Korea, since its introduction in 2010, the PCV13 seems to be more effective than the PCV7. ${ }^{23)}$ In a French study evaluating the effectiveness of the PCV13 in pediatric patients, 1 month to 15 years of age who were radiologically diagnosed with pneumonia at the ED between 2009 and 2012, the prevalence of CAP decreased by 16\% after the introduction of PCV13, with a 63\% decrease in pneumococcal pneumonia and a 53\% decrease in pleural effusion. The decreased prevalence of CAP was more evident in children under the age of 2 years. ${ }^{23)}$

The PCV7 was introduced in Korea in November 2003, with the PCV10 and PCV13 introduced in June 2010 as an optional. In May 2014, PCV10 and PCV13 were incorporated in the national immunization program in Korea. ${ }^{211}$ With regard to the immunization rate achieved, about $40 \%$ of the candidates for vaccination are estimated to have received the PCV7 as of 2007..$^{15)}$ The 2011 national immunization rate survey of 3-year-old children (born in 2007) reported a PCV vaccination rate of $67.1 \%$ for the first dose, $60.5 \%$ for the second dose, $56.7 \%$ for the third dose, and 51.4\% for the fourth dose, with a complete vaccination rate of $49.7 \% .{ }^{24)}$ The 2013 national immunization rate survey of three-year-old children (born in 2009) showed an increased rate of PCV vaccination, with a vaccination rate of 83.4\% for the first dose, $80.5 \%$ for the second dose, $77.8 \%$ for the third dose, and 70.4\% for the fourth dose..$^{25)}$ Although we could not evaluate immunization rate among the patients included in our analysis, we were able to confirm a vaccination rate of 50\% among 3 years old in our 2007 cohort, which increased to about 70\% for this age group in 2013. A limitation of our data set, which spans 2007-2014, is the difficulty in determining if the decline in pleural effusion and empyema could be explained by an increase rate of vaccination with the PCV7 or the introduction of the PCV10 and the PCV13 in 2010. The cyclical MP epidemic in Korea also influences the prevalence of pneumonia, making difficult to clearly distinguish the effects of PCV7 from those of the PCV10 or the PCV13.

Currently, we only identified a lowering in the prevalence of pneumonia types caused by serotypes included in the PCV7, with S. pneumoniae strains that cause invasive infection becoming less frequent, as well as being less frequently identified in oropharyngeal swabs obtained from healthy children. ${ }^{15,19)}$ Overall, however, there is a paucity of data regarding changes in the incidence of pneumococcal infections in children in Korea after the introduction of the PCV10 and the PCV13, as well on the overall effects of these vaccines. ${ }^{26)}$ A detailed evaluation of the effects of pneumonia vaccines in Korea is challenging as it requires accurate specimen collection and identification of bacteria, as well as laboratories and researchers to support the entire research process. Nevertheless, our analysis of a relatively large cohort of children with pneumonia over an 8-year period does provide evidence of a declining prevalence of bacterial pneumonia, pleural effusion and empyema with the 
exception of a unique spike in prevalence in 2011. Our findings provide preliminary evidence of the probable contribution of the PCV vaccination program in lowering the risk for pneumonia in children and adolescents.

However, there is a significant increase in deaths per 10 million populations between the ages of 13 and 18, and the increasing trend of hospitalization for ICU between the ages of 7 and 12 is very worrisome. Active vaccination is needed and studies and countermeasures against the increase of antibiotic resistant bacteria are needed.

The rate of ICU admission in this study varied greatly with age groups, with those $<1$ and 13-18 years of age showing particularly high ICU admission rates. Infants $<1$ year of age also had high rates of ED hospitalization, presumably due to factors related to their age. Newborn and infants $<1$ year of age accounted for the highest proportion of pediatric patients diagnosed with aspiration pneumonia, because of their physiological tendency for gastro esophageal reflux. ${ }^{27)}$

The yearly ICU admission rate declined over the study period, from 2007 to 2014. Domestic humidifier disinfectants were used until 2011, therefore severe interstitial lung disease was nationally prevalent. Since 2011, the use of humidifier disinfectants has been banned, severe interstitial lung disease has been reduced. It would have contributed in part to the reduction in the hospitalization rate of pneumonia and the rate of admission to the ICU. ${ }^{28)}$

In this study, bacterial pneumonia and empyema found significant seasonality in December and May, respectively. This is similar to the results of previous studies in other areas of PCV introduction and the cause of seasonality in pneumococcal disease. ${ }^{29,30)}$ These results suggest that prevention of severe pneumonia complications, vaccination and health measures are needed more.

The findings of this study are limited by the use of NEDIS data, which is based on the diagnoses written in the medical records from the ED. It did not include those who were treated in outpatient clinics or those who were hospitalized through outpatient clinics; therefore, it did not reflect the total number of pneumonia patients. The reliability of diagnosis and treatment may be limited by the proficiency of primary care physicians. We do not know about the vaccination status of the subjects. The incidence of pneumococcal pneumonia was decreased, but no significant decreasing trend was found in frequency per 100,000 population.

Nevertheless, as the first nationwide analysis regarding the trend of pediatric pneumonia over the course of 8 years and within the context of naturally occurring epidemics of influenza and $M$. pneumoniae, we provide an evidence of a benefit of PCV vaccination in Korea in lowering the prevalence of pediatric bacterial pneumonia. We also confirmed an increase in bacterial pneumonia, pleural effusion, and empyema during the MP epidemic breakout in 2011, which calls for prudence during data analysis due to the substantial overlap in the clinical manifestation of bacterial pneu- monia and M. pneumoniae infection.

\section{Conflicts of interest}

No potential conflict of interest relevant to this article was reported.

\section{Acknowledgments}

We thank to the National Emergency Department Information System.

\section{References}

1. Jain S, Williams DJ, Arnold SR, Ampofo K, Bramley AM, Reed C, et al. Community-acquired pneumonia requiring hospitalization among U.S. children. N Engl J Med 2015;372:835-45.

2. Michelow IC, Olsen K, Lozano J, Rollins NK, Duffy LB, Ziegler T, et al. Epidemiology and clinical characteristics of community-acquired pneumonia in hospitalized children. Pediatrics 2004;113:701-7.

3. Lee JH, Cho HK, Kim KH, Kim CH, Kim DS, Kim KN, et al. Etiology of invasive bacterial infections in immunocompetent children in Korea (1996-2005): a retrospective multicenter study. J Korean Med Sci 2011;26:174-83.

4. Yum HY, Kim WK, Kim JT, Kim HH, Rha YH, Park YM, et al. The causative organisms of pediatric empyema in Korea. Korean J Pediatr 2007;50:33-9.

5. Lee YH, Shin YL, Suh WS, Shin MY, Park JO. A clinical study of lobar/lobular pneumonia in children. Pediatr Allergy Respir Dis 2009; 19:271-81.

6. Murray J, Agócs M, Serhan F, Singh S, Deloria-Knoll M, O’Brien K, et al. Global invasive bacterial vaccine-preventable diseases surveillance--2008-2014. MMWR Morb Mortal Wkly Rep 2014;63: 1159-62.

7. Population statistics based on resident registration. [Internet]. Daejeon (Korea): Korean Statistical Information System; 2007 [cited 2016 Nov 20]. Available from: http://kosis.kr/statisticsList/statisticsList_01List. jsp?vwcd=MT_ZTITLE\&parentId=A.

8. Kim JW, Seo HK, Yoo EG, Park SJ, Yoon SH, Jung HY, et al. Mycoplasma pneumoniae pneumonia in Korean children, from 1979 to 2006-a meta-analysis. Korean J Pediatr 2009;52:315-23.

9. Kim SH, Jung SW. Properties of M. Pneumoniae infections in Korea, 2011. Public Health Wkly Rep 2011;4:893-907.

10. Kim EK, Youn YS, Rhim JW, Shin MS, Kang JH, Lee KY. Epidemiological comparison of three Mycoplasma pneumoniae pneumonia epidemics in a single hospital over 10 years. Korean J Pediatr 2015; 58:172-7.

11. Lim JS, Woo SI, Kwon HI, Baek YH, Choi YK, Hahn YS. Clinical characteristics of acute lower respiratory tract infections due to 13 respiratory viruses detected by multiplex PCR in children. Korean J Pediatr 2010;53:373-9.

12. Shin YS, Kang DS, Lee KS, Kim JK, Chung EH. Clinical characteristics of respiratory virus infection in children admitted to an intensive care unit. Allergy Asthma Respir Dis 2013;1:370-6.

13. Choi EH, Lee HJ, Kim SJ, Eun BW, Kim NH, Lee JA, et al. The associa- 
tion of newly identified respiratory viruses with lower respiratory tract infections in Korean children, 2000-2005. Clin Infect Dis 2006;43: 585-92.

14. Roh EJ, Jin YM, Chung EH, Rheem I, Kim JK. The prevalence of respiratory viral infection in exacerbation of asthma in hospitalized children. Korean J Asthma Allergy Clin Immunol 2007;27:241-7.

15. Choi E. Direct and indirect effects of pneumococcal protein conjugate vaccine. J Korean Med Assoc 2008;51:119-26.

16. O'Brien KL, Santosham M. Potential impact of conjugate pneumococcal vaccines on pediatric pneumococcal diseases. Am J Epidemiol 2004;159:634-44.

17. Centers for Disease Control and Prevention (CDC). Direct and indirect effects of routine vaccination of children with 7-valent pneumococcal conjugate vaccine on incidence of invasive pneumococcal disease-United States, 1998-2003. MMWR Morb Mortal Wkly Rep 2005;54: 893-7.

18. Choi EH, Kim SH, Eun BW, Kim SJ, Kim NH, Lee J, et al. Streptococcus pneumoniae serotype 19A in children, South Korea. Emerg Infect Dis 2008;14:275-81.

19. The Korean Pediatric Society. Immunization guideline. 8th ed. 2015: 141-62.

20. Lee JB, Whang KT, Kim JH, Ko KO, Cho JH, Yoo YD. Clinical change of Mycoplasma pneumonia. J Korean Pediatr Soc 1998;41:315-22.

21. Yang EA, Gang MH, You SY, Kim JH, Lee JH. Clinical characteristics of children with lobar pneumonia caused by Mycoplasma pneumoniae. Pediatr Allergy Respir Dis 2012;22:256-64.

22. Chiu CY, Chen CJ, Wong KS, Tsai MH, Chiu CH, Huang YC. Impact of bacterial and viral coinfection on mycoplasmal pneumonia in childhood community-acquired pneumonia. J Microbiol Immunol Infect 2015;48:51-6.
23. Angoulvant F, Levy C, Grimprel E, Varon E, Lorrot M, Biscardi S, et al. Early impact of 13-valent pneumococcal conjugate vaccine on community-acquired pneumonia in children. Clin Infect Dis 2014;58: 918-24.

24. Lee SG, Jeon SY, Ki M, Kim CH, Park EY, Bae GR, et al. Vaccination coverage rate among 3 year olds (cohort born in 2007) using Korea national immunization survey method. J Korean Matern Child Health 2013;17:62-78.

25. Yang HI, Park EY, Kim MY. National immunization survey in South Korea, 2013. Public Health Wkly Rep 2014;7:449-54.

26. Choe YJ, Choi EH, Lee HJ. The changing epidemiology of childhood pneumococcal disease in Korea. Infect Chemother 2013;45:145-58.

27. Lee CH, Won YK, Roh EJ, Suh DI, Chung EH. A nationwide study of children and adolescents with pneumonia who visited Emergency Department in South Korea in 2012. Korean J Pediatr 2016;59:132-8.

28. Paek D, Koh Y, Park DU, Cheong HK, Do KH, Lim CM, et al. Nationwide study of humidifier disinfectant lung injury in South Korea, 1994-2011. Incidence and dose-response relationships. Ann Am Thorac Soc 2015;12:1813-21.

29. Ben-Shimol S, Greenberg D, Hazan G, Shemer-Avni Y, Givon-Lavi N, Dagan R. Seasonality of both bacteremic and nonbacteremic pneumonia coincides with viral lower respiratory tract infections in early childhood, in contrast to nonpneumonia invasive pneumococcal disease, in the pre-pneumococcal conjugate vaccine era. Clin Infect Dis 2015;60:1384-7.

30. Weinberger DM, Grant LR, Steiner CA, Weatherholtz R, Santosham M, Viboud C, et al. Seasonal drivers of pneumococcal disease incidence: impact of bacterial carriage and viral activity. Clin Infect Dis 2014;58: 188-94. 